\title{
Pós-Modernismo e os Ataques à História ${ }^{1}$
}

\section{Post-Modernism and the Attacks against History}

\section{Artigo \\ Original}

\section{Original}

Paper

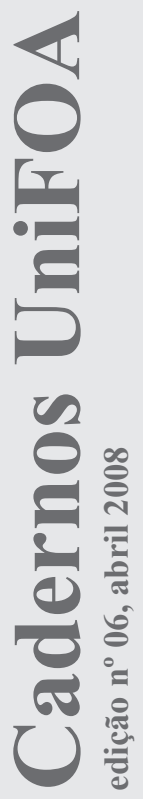

\begin{abstract}
Alexandre de Sá Avelar ${ }^{1}$
Palavras-chaves:

Pós-modernismo

Historiografia

Conhecimento

Histórico

Teoria da

História.

\section{Resumo}

O presente artigo tem como principal objetivo apresentar e discutir alguns impactos da filosofia pós-moderna sobre a possibilidade do conhecimento histórico. Para tal, considerará que o paradigma pós-moderno tornou-se um referencial terórico-conceitual cuja relevância nao pode mais ser negada pela comunidade de historiadores profissionais. Serão abordados, de forma mais sistemática, dois aspectos fundamentais: a insuficiência de uma autoreflexão histórica por parte dos pós-modernos e a negação da capacidade da disciplina histórica de oferecer análises e sínteses de caráter globalizante. Por fim, procurar-se-á defender a idéia de uma história racional, cujos métodos e procedimentos empíricos apontam na direção da possibilidade epistemológica de sínteses explicativas.
\end{abstract}

Key words:

Pos-modernism

Historiography

Historical

Knowledge

History Theory

\section{Introdução}

“ Narrar o passado, repensar a História", lançado em 2000 por professores e estudantes de pós-graduação em História da Universidade Estadual de Campinas, é um dos mais importantes trabalhos já realizados no Brasil a respeito dos impactos causados pelo paradigma pós-moderno ${ }^{2}$ sobre os estudos históricos. De grande rigor analítico, a obra se propõe a estudar várias áreas temáticas específicas. Escrita da história, discurso, fato e narratividade, ciência e ficção, literatura e história, tempo e temporalidade são discutidos através das formulações de Michel Foucault, Gilles Deleuze, Jacques Derrida, Roland Barthes, Hayden White, Dominick La Capra, entre outros.
Entre os diversos autores da coletânea, predomina a idéia de que o fazer historiográfico sofreu modificações profundas nas últimas décadas, como resultado da retomada e/ou redescoberta das temáticas acima mencionadas. A história não é simplesmente um amontoado de fatos passados à espera de que o historiador os leve até a luz e, dada sua pluralidade, não se pode furtar à reflexão sobre seus discursos e representações, indagando-se, por exemplo, sobre os processos incorporados e as práticas sociais que envolvem a construção do objeto histórico, este tomado muito mais como uma obra do que como realidade dada.

As preocupações acima não são novas e estavam, em grande medida, na 
agenda do grande movimento de renovação da historiografia ocidental do século XX, os Annales. Não se pode negar ainda que a produção do conhecimento histórico sempre recebeu contribuições cruciais da linguística, antropologia, psicanálise, entre outros campos do saber, enriquecendo em muito as análises disponíveis sobre os mais diversos objetos e colaborando para a consolidação de um status científico para a disciplina. A interdisciplinaridade constituia-se, assim, num dos mais importantes instrumentos de escrita da história, possibilitando uma compreensão holística do social em seus diferentes níveis, eliminando, ou ao menos afastando, o fortuito e o irracional da narrativa histórica.

A visão de que a reconstrução de um objeto histórico deve levar em conta sua dimensão totalizante, através da incorporação dos saberes produzidos em outros campos do conhecimento e se utilizando, sempre que possível, de métodos de investigação cientificamente conduzidos, foi denominada por Ciro Cardoso ( 1997 ) de "paradigma iluminista" e suas expressões mais significativas na historiografia foram as duas primeiras gerações dos Annales e o marxismo. Comum a essas tendências era a convicção da possibilidade de construção de uma ciência histórica analítica, estrutural e voltada para a inteligibilidade da ação humana. Essas perspectivas foram hegemônicas entre os historiadores até pelo menos a década de setenta, a partir de quando passaram a sofrer um nítido recuo com a emergência da chamada Nova História.

Visto em conjunto, o paradigma iluminista jamais abdicou de contribuições dos demais campos do conhecimento e, sendo assim, aqueles que analisam os impactos da crítica literária ou da lingüística sobre os estudos históricos não estão apontando para novidades concretas. Então, qual a especificidade das abordagens pós-modernas na historiografia? Que papel mais geral para a história é dado por uma concepção que privilegia o enfoque fragmentário e não-progressista da vida social? Tais perguntas talvez nos levem a uma outra, de escopo mais largo. O que a história de uma perspectiva analítica e totalizante ainda pode nos oferecer como caminho de investigação e compreensão dos desafios sociais, políticos e econômicos do século XXI?

Desnecessárioafirmarqueashipóteses aqui levantadas não pretendem esgotar o arsenal de respostas e análises oferecidas para as questões propostas. A vasta e significativa bibliografia sobre o tema sugere a inexistência de um único feixe de investigações, mas uma complexa heteregoneidade de interpretações, interesses e tensões que circundam nosso objeto em debate. O que temos em vista neste artigo é de ambição bem mais modesta. Cremos que as propostas do pós-modernismo no tocante à história - entendida tanto como o desenrolar do tempo histórico quanto disciplina acadêmica - podem ser entendidas a partir do que chamaremos de um "duplo ataque", a saber, a negação da análise histórico- temporal para a compreensão do pós-modernismo e a negação da validade de paradgimas historiográficos totalizantes e de metanarrativas epistemológicas. A recuperação do pós-modernismo como objeto histórico dotado de uma lógica temporal definida a partir do conjunto de transformações ocorridas na economia capitalista dos anos 70 e a análise crítica da desconstrução do racionalismo na produção do conhecimento histórico constituem-se nas principais linhas argumentativas utilizadas na defesa contra aqueles ataques.

\section{O objeto histórico chamado pós- modernismo:}

Como bem destacou Ellen $\mathrm{M}$. Wood ( 1999 ), as descrições atuais do pósmodernismo guardam grande semelhança com as tradicionais abordagens de declínio da civilização ocidental, sendo os trabalhos de Oswald Spengler e C. Wright Mills os exemplos mais significativos. Uma diferença se faz notável, entretanto: enquanto estes autores procuraram dar um enfoque histórico as suas abordagens, os pós-modernistas apresentam suas teorias com total ausência de perspectiva temporal, fazendo-as surgir como reflexos de uma certa paisagem contemporânea isenta de ideologias e marcada pelo declínio da esperanças políticas de emancipação humana. Afigura-se aqui o que entendemos como o primeiro ataque do pós-modernismo em relação à história: a não consideração de que a afirmação e expansão entre os meios acadêmicos e culturais de um certo "espírito pós-moderno" tem raízes concretas e de que 
estas se ligam a profundas transformações ocorridas nos padrões de acumulação capitalista a partir do final dos anos sessenta, redefinindo uma lógica cultural inerente à nova realidade do capitalismo financeiro-global.

Os anos imediatos após a II Guerra foram marcados por forte expansão das forças produtivas capitalistas que passaram a contar com uma ação cada vez mais firme dos Estados Nacionais no sentido de assegurar sua reprodução. O que havia ficado claro das experiências anteriores era que o simples funcionamento das forças de mercado não bastava para garantir os níveis de acumulação necessários à manuntenção da ordem interna dos países de capitalismo avançado e tampouco favorecia o entendimento internacional entre as principais potências. Tornava-se necessário, portanto, forjar um novo modelo no qual o Estado surgisse como ente regulador básico no controle da crises, através da manutenção de taxas de lucros compatíveis com as demandas dos trabalhadores, garantia de emprego e consumo para as massas populacionais. Situação histórica muito bem sintetizada por José Luis Fiori ( 1995: 3 )

\footnotetext{
Consolidada a Pax Americana, depois de 1945, consagra-se o grande acordo que tem, como sua pedra angular, o Estado enquanto organizador do pacto corporativo entre governo, sindicatos e capital, e, responsável, em grande medida, pelo surto de crescimento acompanhado de paz social que, nos anos 50 e 60 , alimentou a utopia de uma sociedade estável de consumo de massas, com bem-estar e liberdade para todos.
}

Tais padrões de crescimento industrial e melhoria das condições sociais através de ações públicas estatais tiveram abalo significativo com a chamada crise dos anos setenta, iniciada pela crise do petróleo, seguida pela retomada da hegemonia norteamericana ancorada na diplomacia do dólar forte e no incremento do seu poderio militar ( TAVARES,1997: 29 ). Redefinem-se novos canais de crescimento do capital, e sua base financeira passa a estimular o processo de globalização capitalista, exigindo nova disciplina fiscal dos Estados Nacionais, rompendo o pacto mediador entre capital e trabalho, com evidentes desvantagens para o segundo.

Esse padrão mais flexível de acumulação financeira foi acompanhado de inovações significativas nas tecnologias de informação, com avanços decisivos na eletrônica, nas redes midiáticas, na automação, no marketing, etc., Simultaneamente, o regime de produção industrial torna-se altamente flexível e mesmo não se podendo afirmar a existência deumaeconomiamundial controlada inteiramente por firmas transnacionais ( HIRST e THOMPSON, 1998 ), é inegável o fato de que ocorreu uma diversificação na distribuição espacial das empresas acompanhada de reformas nas estratégias de produção - para muitos o fenômeno conhecido como pós-fordismo. Paralelamente, assistese a uma redução cada vez mais acentuada do proletariado - com todas as implicações políticas que o fenômeno acarreta - com aumentos dos níveis de desindustrialização em diversas áreas do sistema capitalista. Novos padrões sociais e culturais forjam-se ao calor das mudanças operadas na ordem econômica, as quais o sistema soviético parecia incapaz de responder.

O fim do consenso keynesiano alargou as bases para a emergência de uma economia mundial flexível e de novas formas de pensamento político-social. Tornava-se claro para muitos intelectuais que a capacidade de adaptação do modo de produção capitalista era um sintoma de sua superioridade em relação ao seu adversário comunista. Tal hipótese seria confirmada pouco mais de uma década depois com o desmoronamento do socialismo real, primeiro na Europa Oriental e depois no núcleo soviético. O triunfalismo da economia de mercado e da democracia política liberal confirmava a idéia de que a evolução da humanidade em direção a níveis cada vez maiores de progresso e realização material chegava, nesse momento, a um termo decisivo. Esgotava-se, dessa forma, toda a crença no devir histórico, não sem as agruras de duas guerras mundiais, uma crise sistêmica sem precedentes do capitalismo e a ascensão de regimes de forte coloração totalitária, tanto à esquerda quanto à direita. A vitória americana representava, a um só tempo, a realização e a liquidação do projeto iluminista. Decretavase, dessa forma, o fim das grandes narrativas ideológicas - marxismo e liberalismo - , o declínio das utopias e a era do conformismo político.

Este último ponto mereceu considerações importantes de autores como 
Alex Callinicos e Fredric Jameson. Para o primeiro, as razões mais profundas do surgimento de uma visão pós-moderna deviamse não tanto às mudanças ocorridas no sistema de integração do capital - não se tratava de forma alguma de uma ruputra histórica -, mas à derrota política da geração radical dos anos 60. Com suas esperanças frustradas, muitos intelectuais encontraram refúgio no mundo tranquilo da expansão do consumo e dos padrões capitalistas, alimentando as correntes pós-modernas de negação das versões progressistas e emancipadoras das grandes narrativas explicativas dos nossos tempos (Citado em ANDERSON, 1999 ).

Para Jameson, a expansão do capitalismo após a II Guerra, através da regulação estatal das taxas de acumulação e consolidação do Welfare State, produziu uma imensa liberação de energias sociais, "uma prodigiosa escapada de forças não-teorizadas: as forças étnicas dos negros e das 'minorias' ou dos movimentos que eclodiram por toda parte no Terceiro Mundo, os regionalismos, o desenvolvimento de novos e militantes portadores de surplus consciousness nos movimentos estudantis e de mulheres, bem como um sem-número de lutas de outros tipos". Essas novas forças pareciam demonstrar que os graus de liberdade e luta política poderiam emergir fora dos padrões de classe tratados pelo marxismo. A crise posterior colocaria os anos 60 como um momento possível de transição de um estágio infra-estrutural ou sistêmico do capitalismo para outro. O desafio social da contemporaneidade é recuperar os impulsos libertários da década de 60, a partir da transformação em luta de classes daquelas forças libertárias, unificando-as, pois, "a força unificadora é a nova vocação de um capitalismo doravante global do qual também se pode esperar que unifique as resistências desiguais, fragmentadas ou locais, ao processo" ( JAMESON, 1991: 126 ).

Esses fenômenos relacionados nos parágrafos anteriores tiveram impactos decisivos nas vidas de todos países desenvolvidos do mundo capitalista e alargaram-se para as formas de consciência dessas sociedades. Nesse ponto, tem-se o contato decisivo entre um regime de acumulação flexível de capital e as mutações no espaço e nas configurações culturais. É o momento, segundo Perry Anderson (1999: 66
) em que " a modernização estava agora quase concluída, apagando os últimos vestígios, não apenas de formas sociais pré-capitalistas como de todo território natural intacto, de espaço ou experiência, que as sustentara ou sobrevivera a elas". Para Jameson ( 1991 ), os últimos campos pré-capitalistas tragados agora pelo capitalismo tardio eram o Terceiro Mundo e o inconsciente.

Dentro da lógica de uma ordem econômica cada vez mais financeirizada e suas transfigurações no campo das representações culturais, é importante não ignorar que os avanços tecnológicos representaram um papel de destaque. Novamente, Anderson (1999:68) nos oferece uma interpretação lúcida a respeito:

\footnotetext{
A unificação eletrônica da Terra, instituindo a simultaneidade de eventos mundo afora como espetáculo diário, instalou uma geografia substituta nos recessos de cada consciência, enquanto as redes circundantes de capital multinacional que efetivamente dirigem o sistema ultrapassam a capacidade de qualquer percepção. A ascendência do espaço sobre o tempo na constituição do pósmoderno está assim sempre em desequilíbrio, com as realidades a que responde constitutivamente sobrepujando-a - induzindo, como sugere Jameson numa passagem famosa, essa sensação de que só se pode captar com uma sardônica atualização da lição kantiana: "o histérico sublime".
}

A paisagem da qual se originaram as formulações do pós-modernismo tem, portanto, bases materiais bem definidas. Insere-se nas mudanças ocorridas na economia mundial a partir dos anos setenta, nas inovações tecnológicas e nos refluxos dos movimentos políticos de massa e dos ideais iluministas de progresso e emancipação. A natureza simbiótica entre o funcionamento da cultura e da economia no mundo contemporâneo foi dessa forma sintetizada por Jameson ( 2000:14 ):

Nos últimos anos tenho argumentado com insistência que tal [ a atual ] conjuntura é marcada pela desdiferenciação de campos, de modo que a economia acabou por coincidir com a cultura, fazendo com que tudo, inclusive a produção de mercdorias e alta especulação financeira, se tornasse cultural, enquanto que a cultura tornou-se profundamente econômica, igualmente orientada para a produção de mercadorias. Portanto, não devemos nos surpreender com o fato de que conjecturas sobre o nosso assunto em questão podem na verdade ser tomadas como afirmações 
Esse processo histórico tornou o pós-modernismo- o "consumo da própria produção de mercadorias- como processo" ( JAMESON, 2000: 14 ). Recuperar as condições concretas pelas quais possamos apreender a historicidade do pós-modernismo como objeto de análise, torna-se o primeiro passo para "pensar o presente historicamente em uma época que já esqueceu como pensar dessa maneira"( JAMESON, 2000: 12 ) retomando o pensamento crítico em relação às estratégias de disseminação de novos padrões de dominação cultural, econômica, política e social.

\section{Pós-modernismo e os impactos na disciplina histórica}

Ao se propor como negação das narrativas libertárias e progressistas, a filosofia pós-moderna desferiu um grave golpe contra a história-disciplina; ela também deve esquecer suas expectativas de explicação totalizante, duvidar de sua ambição científicoracionalista e conformar-se com a idéia de que o conhecimento se reduz a processos hermenêuticos, nos quais inexistem critérios de hierarquização e, portanto, inexistem também formas de validação criteriosa das interpretações, sendo todas igualmente válidas.

Entenderemos aqui, esse conjunto de pressupostos mencionados acima, como o segundo ataque do pós-modernismo à história, atingindo agora sua dimensão de disciplina racional e explicativa da realidade social. Na parte anterior, sugerimos que o pósmodernismo buscou erigir-se como categoria de pensamento, dando pouca atenção aos condicionantes materiais que conformavam uma virada nas formas de captar os movimentos culturais e artísticos pretensamente formadores de uma era pós-moderna. Identificamos, grosso modo, esses condicionantes aos movimentos de financeirização capitalista, à diluição das ordens sociais tradicionais e à era de derrocada dos grandes movimentos políticos que marcaram os anos 60 . Isso nos possibilitou recuperar a historicidade perdida do objeto chamado pós-modernismo.
Retornemos à disciplina histórica. O pensamento histórico sofreu um amplo processo de modernização de suas estruturas cognitivas a partir do pressuposto básico de que é a razão a estratégia metódica informadora de nossas incursões ao passado. Tal perspectiva inaugura-se evidentemente com o Iluminismo, estende-se ao ambicioso programa de cientifização da História com o historicismo do século XIX e consolida-se na primeira metade do século passado com os Annales e com o marxismo. Evidentemente, são vastas as diferenças teórico-conceituais e metodológicas entre essas correntes, mas elas estavam em acordo num ponto essencial: a construção do conhecimento histórico é um processo racional, cientificamente informado e com procedimentos previamente convencionados de análise de fontes e de formulação de explicações. Trata-se de uma entidade efetiva que se compõe no passado, presente e futuro em uma totalidade abrangente. O fio condutor está na idéia de uma lógica de desenvolvimento inerente ao processo histórico, o que poderíamos entender como noção de progresso.

Esses fundamentos receberam críticas sistemáticas dos pós-modernistas. Ciro Cardoso ( 1997:15 ) utilizou-se de uma citação de Keith Jenkins para situar a definição mais cabal do paradigma pós-moderno no interior da história-disciplina:

\footnotetext{
A história é um discurso mutável e problemático - ostensivamente a respeito de um aspecto do mundo, o passado - produzido por um grupo de trabalhadores cujas mentes são de nosso tempo ( em grande maioria, em nossa cultura, historiadores assalariados ) e que fazem seu trabalho em modalidades mutuamente reconhecíveis e que são posicionados epistemológica, ideológica e praticamente; e cujos produtos, uma vez em circulação, estão sujeitos a uma série de usos e abusos logicamente infinitos mas que, na realidade, correspondem a uma variedade de bases de poder existentes em qualquer momento que for considerado,as quais estruturam e distribuem os significados das histórias ao longo de um espectro que vai do dominante ao marginal
}

O processo de transformação da história em uma disciplina instucional e cientificamente reconhecida deixou de lado os aspectos literários do discurso histórico em nome de corretos métodos de interpretação das fontes, de leis de causalidade e teorias de 
explicação do devir humano. Isso representava uma ordem do discurso visto como "um fato social que visava a institucionalizar certas formas de indagação, de reflexão e mesmo de expressão; o que implica diretamente expulsar e mesmo interditar outras" ( LIMA, 1989: 60 ). A grande recusa era a escritura narrativa da história. A síntese de Bennati ( 2000: 82 ) é significativa

$\mathrm{Na}$ produção do conhecimento histórico, o rigor dos métodos de investigação e erudição, o papel do documento como atestado de veracidade dos fatos ( uma concepção estritamente jurídica da prova ), a depuração das fontes, a extinção da subjetividade, tudo isso parecia sufuciente para afastar a história do puramente imaginativo e ficcional, assegurando para ela um lugar digno no concerto das triunfantes ciências sociais.

A representação dessa recusa tornou os historiadores inconscientemente cegos ao caráter retórico-po(i)ético do seu discurso. Os modelos de escrita acadêmica tornaram-se um cânone, uma espécie de ortodoxia da forma que impediu justamente a reflexão sobre a forma, isto é, sobre os dispositivos literários que os "cientistas", devido ao uso inevitável da linguagem verbal, agenciam no seu discurso e materializam no seu texto

A volta da narrativa ao discurso histórico constituiu-se num dos temas preferidos entre os estudiosos, identificados com as visões pós-modernas da história. Lawrence Stone relacionou esse retorno ao fracasso dos três modelos centrais da ciência da história na primeira metade do século XX - o marxismo, a escola demográfica e a escola estatística dos historiadores norte-americanos “cliometricianos". Mas não apenas fatores internos ao debate historiográfico explicavam o ressurgimento da literatura nos estudos históricos. O declínio das expectativas de que as grandes narrativas pudessem gerar movimentos concretos de emancipação, o decrescente compromisso ideológico dos historiadores e a necessidade de falar a um público cada vez mais ampliado pela explosão consumista colocavam limites ao cientificismo da historiografia erigida com as linhas mestras dos Annales e do marxismo.

$\mathrm{O}$ reconhecimento da narrativa implicava aceitar que o que o historiador produz se assemelha a um texto literário carregado de retórica e com pretensões de persuasão. Em última instância, todo discurso histórico
- desde a mera crônica dos acontecimentos até aquela mais social, estrutural ou quantitativa - é dependente de procedimentos próprios de composição de uma narrativa. Mesmo entre os historiadores que sempre acreditavam estar fazendo ciência, os elementos literários jamais estiveram ausentes, mas eram ou camuflados em nome da razão ou hostilizados como ficção ou irracionalismo.

Para os pós-modernos, tornava-se evidente que os esquemas de análise rígidos e, na maioria dos casos economicista, dos "historiadores cientistas" davam pouca margem para a apresentação dos elementos de escrita literária subjacentes a todo discurso. Assim, abrem-se para novas temáticas e novos objetos mais suscetíveis à recepção da literatura. Histórias da sexualidade, das mentalidades ou das mulheres surgem, dessa forma, como objetos abertos à contribuição das formas literárias, revelando a pouca atençao que a historiografia tradicional dedicava à narrativa e às demais formas de identidade social ou sexual.

A estética e a epistemologia pósmoderna tornaram frágeis as separações entre o "real " e o "ficcional". A crítica inicia-se justamente pela noção de passado. Os adeptos do paradigma pós-moderno não negam a existência de um passado que efetivamente existiu, mas põem dúvidas quanto a nossa capacidade de apreendê-lo fora da produção de um dado discurso textual. Isso porque todos os documentos usados pelos historiadores na pesquisa empírica são vestígios textualizados do passado. O referente real já existiu, mas hoje ele só nos é acessível pela linguagem, neste caso, a matéria bruta de todo o conhecimento histórico.

Noâmbitodasreflexõesencaminhadas pela pós-modernidade, a figura do historiador como indivíduo imparcial e objetivo por excelência - se é que já tivemos algo próximo disso alguma vez - é desconstruída. De fato, esse sujeito supostamente neutro é também uma construção histórica, enfeixado numa rede de instituições, lugares de fala e interações. Seu discurso não pode, portanto, refletir a realidade, mas ele mesmo contribui para instaurá-la. Segundo Paul Veyne ( 1983: 48 ):

... os fatos não existem isoladamente, no sentido de que o tecido da história é o que chamaremos uma 
intriga, uma mistura muito humana e muito pouco "científica"de causas materiais, de fins e de acasos; numa palavra, uma fatia da vida, que o historiador recorta a seu bel-prazer e onde os fatos têm as suas ligações objetivas e sua importância relativa

Assim, o que podemos conhecer dos fatos do passado são as representações textuais dadas pelos historiadores. E essas representações são, acima de tudo, literárias, nas quais não se pode obscurecer o papel criativo do produtor do discurso histórico. Para Hayden White ( 1994: 70 ), "os historiadores explicam os eventos que compõem as suas narrativas por meios especificamente narrativos de codificação, isto é, descobrindo a estória que está encerrada nos eventos ou por trás deles e contando-a de uma maneira que um homem medianamente culto possa entender".

Uma atitude extrema apresentar-se-ia comoanegaçãodaprópriahistória, diluídaassim em "histórias" produzidas por grupos sociais claramente identificados ( os historiadores ) com interesses próprios e inseridas numa cadeia de relações de poder. Assim, todo o saber produzido é necessariamente múltiplo, o que escapa à razão científica. Predominam as formas de representação, os "níveis de discursividade", demonstrando a incapacidade de uma análise estrutural e analítica. Assim, o historiador deveria voltar-se aos ensaios de microinterpretação, à valorização dos aspectos condicionantes das interações com seu objeto, enfim, um conformismo com a impossibilidade da metanarrativa científica.

\section{Em defesa da história: as defesas contra os ataques do pós-modernismo.}

Os ataques partidos do pósmodernismo à história não podem ficar sem respostas. O que está em jogo é uma longa e árdua luta de construção de um arcabouço teórico e metodológico que trouxe a possibilidade de um conhecimento científico do todo social, através dos instrumentos da razão. Entendemos que os dois ataques aqui estudados - a insistência em dissolver a historicidade do pós-modernismo em meio às formulações difusas a respeito de uma ruptura com o modernismo e a negação da possibilidade de entendimento histórico- totalizante do real - representam um claro avanço de uma concepção conformista e irracionalista do processo contemporâneo de transformações na base do sistema capitalista, a partir da proeminência do discurso e da narrativa sobre a experiência humana vivida. Assim, essa própria experiência é discursiva e suas representações são múltiplas e impossíveis e válidas para todos os casos. Em último caso, o relativismo total nos levaria a duvidar da própria existência efetiva de categorias como sistema capitalista, modo de produção, etc.

Contudo, o que se observa é a relação profunda entre os postulados pós-modernistas e as transformações do capitalismo contemporâneo em sua extensão da mercadoria a todos os níveis da sociedade e a todos os espaços territoriais. Proceder a essa análise histórica na compreensão da lógica econômica do pós-modernismo é a resposta ao primeiro ataque.

Aresposta ao segundo ataque constitui uma tarefa mais árdua, pois são exatamente nas críticas à história-disciplina que os teóricos do pós-modernismo têm logrado mais êxito. É inegável o prestígio de autores como Hayden White, LaCapra, Paul Veyne ou os expoentes da chamada Nova História entre a comunidade dos historiadores. Parte desse sucesso tem razões concretas. Muitas de suas análises chamaram a atenção corretamente para os abusos do cientificismo, alertaram os historiadores para a necessidade de ampliação dos seus objetos de estudo e forneceram valiosas interpretações sobre grupos sociais até então ausentes de grande parte das análises disponíveis. Como negligenciar o surgimento de novas identidades étnicas e sexuais, frutos mesmo de experiências humanas bastante diversificadas no interior de um mundo contemporâneo marcado pela indefinição e pela incerteza? E nesse mesmo mundo, é possível deixar de lado a importância da linguagem ou dos símbolos e mesmo a narrativa e a literatura nos discursos dos historiadores?

A resposta para todas as perguntas acima é evidentemente não. Reconhecer as diferenças não significa corroborar a idéia de que as configurações da contemporaneidade não podem ser apreendidas pelos instrumentos de investigação científica e racionalista. Tampouco, a história como uma análise estrutural de longa duração perdeu sua validade. Como compreender um sistema 
global como o capitalismo utilizando-se as categorias fragmentadas e a-históricas do pósmodernismo?

Os pós-modernistas alegam que os esquemas interpretativos totalizantes - como o marxismo - são fechados a temáticas como sexualidade, feminismo ou racismo. Apresentam-se como portadores de uma abordagem mais aberta e atenta aos aspectos negligenciados. Contudo, negam veementemente o conhecimento histórico científico e o uso da razão. Sendo os discursos produzidos através de construções literárias, nos quais não se pode alcançar a verdade, por que um discurso baseado na experiência científico-racional não é válido? Aberturas em nome de novos fechamentos.

Uma outra contradição é visível na postura pós-moderna em relação à história. A narrativa era apresentada como um recurso indispensável pelo qual o historiador apresentava os resultados do seu trabalho. Recordemos ainda que esse sujeito do conhecimento não pode produzir mais do que representações estilísticas da realidade, não estando em condições de alcançá-la em sua totalidade. O todo social cognoscível é, portanto, uma ilusão cientificista. Nesse plano, a narrativa situa-se a priori do real, pois o constrói. Nesse sentido, a narrativa não se sustenta, pois, isolada, não pode pretender erigir-se como conhecimento válido, uma vez que não dispõe de seus contrários. A solução desse equívoco está em recuperar um dos postulados rejeitados pelos pós-modernos: qualquer prática discursiva ou epistemológica está inserida num conjunto de experiências reais ligadas a um todo social que só pode ser analisado se preservada sua dimensão estrutural.

A multiplicação dos temas abordados pelos pós-modernos não esgota a macroanálise. Em polêmica com Lawrence Stone, Eric Hobsbawm afirmava:

Nada há de novo em escolher ver o mundo através de um microscópio e não com um telescópio. Na medida em que aceitamos que estamos estudando o mesmo cosmo, a escolha entre microcosmo e macrocosmo depende de selecionar a técnica apropriada. É significativo que, na atualidade, historiadores mais numerosos achem útil o microscópio; mas isto não significa necessariamente que recusem os telescópios como coisas fora de moda. Até os historiadores da mentalité, este termo vago e que abarca tanto,

que Stone, talvez sabiamente, não tenta esclarecer, não evitam a visão ampla de maneira exclusiva ou predominante. Pelo menos esta lição aprenderam com os antropólogos. ( Citado em CARDOSO, 1988: 108 )

$\mathrm{O}$ que o historiador inglês defende é a impossibilidade de análise de temáticas específicas sem noção do que seja a totalidade do social, sob os riscos de relativismo e desistorização do objeto em estudo. Micro-análises ou monografias específicas se beneficiam das referências estruturais, ampliando a validade de suas teorias e corrigindo desvios de método, como por exemplo, a ênfase no excessivo papel do voluntarismo individualista, no caso da biografia.

Reconhecer a validade do discurso histórico estrutural como uma urgência em tempos de descontrução e relativismo epistemológico é obviamente uma posição política. Faremos nossas palavras finais as de Ciro Cardoso ( 1997: 23 )

\section{Referências}

- ANDERSON, P. As origens da pósmodernidade. Rio de Janeiro: Jorge Zahar, 1999.

- BENNATI, A. P. História, ciência, escritura e política. In: GIMENES, R. A. O. e RAGO, M. (orgs). Narrar o passado, repensar a história. Campinas: UNICAMP, Instituto de Filosofia e Ciências Humanas, 2000.

- CARDOSO, C. F. Ensaios racionalistas. Rio de Janeiro: Campus, 1988.

História e paradigma rivais. In: e

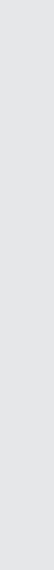

\section{(1)}


ensaios de teoria e metodologia. Rio de Janeiro: Campus, 1997.

- FIORI, J. L. O vôo da coruja: uma leitura não liberal da crise do estado desenvolvimentista brasileiro. Rio de Janeiro: EDUERJ, 1995.

\section{- HIRST, P. e THOMPSON, G. Globalização} em questão. Petrópolis: Vozes, 1998.

- HOBSBAWM, E. A era dos extremos: o breve século XX ( 1914 - 1991 ). São Paulo: Companhia das Letras, 1995.

- JAMESON, F. Pós-modernismo: a lógica cultural do capitalismo tardio. São Paulo: Ática, 2000.

- __ A cultura do dinheiro. Petrópolis: Vozes, 2001.

- __ Periodizando os anos 60. IN: HOLLANDA, Heloísa Buarque de org. Pósmodernismo e política. Rio de Janeiro: Rocco, 1991.

- LIMA, L. C. A aguarrás do tempo: estudos sobre a narrativa. Rio de Janeiro: Rocco, 1989.

- WHITE, H. Meta-História. São Paulo: EDUSP, 1995.

- _ _ _ Trópicos do discurso. São Paulo, EDUSP, 1994.

- WOOD, E. M. O que é a agenda "pósmoderna"? IN: e FOSTER, J. B Em defesa da História: marxismo e pósmodernismo. Rio de Janeiro: Jorge Zahar, 1999.

\begin{abstract}
- TAVARES, M. C. A retomada da hegemonia norte-americana. IN: e FIORI, J. L. (orgs). Poder e dinheiro: uma economia política da globalização. Petrópolis: Vozes, 1998.
\end{abstract}

VEYNE, P. Como se escreve a história. Lisboa: 70, 1983.

\footnotetext{
${ }^{1}$ Este texto foi originalmente apresentado no $\mathrm{X}$ Encontro Regional de História da ANPUH-RJ, realizado na Universidade do Estado do Rio de Janeiro em 2002.

\begin{abstract}
${ }^{2}$ Ao utilizar a categoria de paradigma para se referir ao pós-modernismo, estou me valendo das formulações de Ciro Flamarion Cardoso, para quem há dois grandes paradigmas de interpretação histórica, o iluminista e o pós-moderno. CARDOSO, C. F. História e paradgimas rivais. In: e VAINFAS, Ronaldo. Domínios da História: ensaios de teoria e metodologia. Rio de Janeiro, Campus, 1997.
\end{abstract}

\section{Informação bibliográficas:}

Conforme a NBR 6023:2002 da Associação Brasileira de Normas Técnicas (ABNT), este texto científico publicado em periódico eletrônico deve ser citado da seguinte forma: AVELAR, A. S.. Pós-Modernismo e os Ataques à História. Cadernos UniFOA, Volta Redonda, ano III, n. 6, abril. 2008. Disponível em: <http://www.unifoa.edu.br/pesquisa/caderno/edicao/06/40.pdf> 